\title{
Sección de Medicina del Trabajo de la Unión Europea de Médicos Especialistas (UEMS)
}

\author{
M. C. Rodríguez-Jareño \\ http://www.uems-occupationalmedicine.org
}

DOI: 10.12961/aprl.2017.20.04.5

La primera reunión de 2017 de la sección de Medicina del Trabajo de la Unión Europea de Médicos Especialistas (UEMS)1,2 tuvo lugar en Helsinki los días 26 y 27 de mayo con asistencia de 18 representantes. Los países representados fueron Austria, Bélgica, Dinamarca, Eslovenia, España, Finlandia, Italia, Irlanda, Luxemburgo, Noruega, Países Bajos, Polonia, Portugal, República Checa, Rumanía y Suiza. También asistió la representante de los residentes de Medicina del Trabajo (European Junior Doctors $^{3}$, un representante de EASOM (European Association of Schools of Occupational Medicine $)^{4}$ y el tesorero de la UEMS.

La presidenta de la sección, Alenka Skerjanc, resaltó que esta reunión coincide con diversos aniversarios, como los 100 años de independencia de Finlandia, 70 años del Instituto Finlandés de Salud Laboral, y 20 años de la sección de Medicina del Trabajo de la UEMS (la propia UEMS cumplirá 60 años el próximo año).

En esta ocasión, la Sección de Medicina del Trabajo de la UEMS tuvo el honor de contar con la presencia del Profesor Jorma Rantanen, Presidente de la Comisión Internacional de Salud Ocupacional (ICOH) entre 2003 y 2006, Director General del Instituto Finlandés de Salud Ocupacional hasta 2003, y asesor experto de la Organización Mundial de la Salud (OMS), la Organización Internacional del Trabajo (OIT) y de la Unión Europea (UE). El profesor Rantanen hizo una presentación de su perspectiva sobre "Los desafíos a los servicios de salud laboral mundiales y europeos en la era de la globalización" en la que enfatizó que, a pesar de las deficiencias, Europa es claramente el líder mundial en salud laboral, por delante de Estados Unidos, y muy por delante del resto de países. Eso nos da una responsabilidad mundial, ya que muchos miran a Europa como referente. Aunque la globalización es un concepto complejo, existen instrumentos para medirla, como el índice de Zurich y el de Maastricht, ambos muestran que 12 países europeos (entre ellos España) están entre los 15 primeros en globalización. En relación a las empresas, indicó que la tendencia es que cada vez haya menos multinacionales, pero más grandes y poderosas, mientras que las pequeñas y medianas empresas continúan siendo las que mayor número de puestos de trabajo ofrecen a nivel mundial. En relación a los riesgos, estos son principalmente psicosociales en Europa (inseguridad laboral, estrés crónico, jornadas laborales largas, recortes en personal, liderazgos tóxicos, envejecimiento de la población trabajadora con la necesidad de adaptaciones tanto físicas como mentales, entre otros), mientras que en Asia y África continúan predominando los riesgos clásicos. En los países desarrollados las mejoras en seguridad y salud laboral han reducido los riesgos clásicos, y las exposiciones han disminuido (aunque no desaparecido); también contamos con métodos más sensibles para detectarlos por lo que la realización de evaluación de riesgos se está haciendo más compleja. Todo ello ha contribuido a que disminuyan los accidentes mortales en Europa, pero continúa habiendo una enorme infradeclaración de enfermedades profesionales, y mucho más aún si nos referimos a las enfermedades relacionadas con el trabajo.

Desde una perspectiva global, se estima que más de 2 millones de personas mueren cada año por enfermedades relacionadas con el trabajo, y más de 300.000 (equivalente a 1.000 muertes al día) por accidentes de trabajo. A nivel mundial, la cobertura de Servicios de salud laboral para la población trabajadora se calcula en un 15,5\% como máximo, pero además el acceso es más limitado precisamente para aquellos trabajadores que lo necesitarían más.

La presentación del profesor Rantanen está disponible como anexo 2 en el acta de la reunión que se puede encontrar, como es habitual, en la página web de la sección.

A continuación el Profesor Kari Reijula, de la Universidad de Helsinki y el Instituto Finlandés de Salud Ocupacional, hizo un resumen de la situación de la Salud Laboral en Finlandia, país con una población de 5.5 millones de personas y una población activa de 2.6 millones.

La Medicina del Trabajo en Finlandia requiere una formación especializada de 6 años y es la segunda mayor especialidad en el país; siempre ha tenido una gran presencia y fortaleza como especialidad, y, aunque actualmente se encuentra cuestionada esta supremacía, parece que aguantará a un intento de cambio legislativo cuyo debate está en curso. Los servicios de salud labo- 
ral finlandeses pueden ser propios, ajenos o públicos y cubren a un $79 \%$ de los trabajadores (1.9 millones). Con un presupuesto de 800 millones de euros al año, la financiación proviene en un 99\% de las cotizaciones de empresas y trabajadores y constituye un sistema con una rica distribución geográfica en el territorio y altamente eficiente, trabajando en muchas ocasiones mano a mano con los médicos de familia. De hecho, los servicios de salud ocupacional en Finlandia abordan no solo los aspectos preventivos y de vigilancia de la salud, sino que también tienen un papel asistencial. Este papel se centra principalmente en el diagnóstico y tratamiento de enfermedades profesionales y relacionadas con el trabajo así como accidentes de trabajo, pero también cubre la detección y tratamiento de patología común prevalente entre los trabajadores de las empresas a las que dan cobertura. Para ello, además de médicos y enfermeros del trabajo cuentan con fisioterapeutas y psicólogos.

A continuación el secretario general de la UEMS, Bernard Maillet, hizo un resumen de las últimas actividades de la UEMS a nivel central, y la representante de los residentes de Medicina del Trabajo expuso los resultados de la encuesta sobre formación en los diferentes países europeos.

El representante danés, encargado de la página web de la sección, informó que las visitas a la web han aumentado sensiblemente en el último año (probablemente gracias a que los países han introducidos los enlaces en sus respectivas webs) y recuerda que todas las actas, desde la primera hace 20 años (Glasgow, 25 4-1997) a la última, están disponibles con carácter público en la web de la sección.

El siguiente punto que se trató fue en relación a los exámenes europeos promovidos por la UEMS de acuerdo con las normas $\mathrm{CESMA}^{5}$ que son compartidas por todas las especialidades.

Uno de los objetivos primordiales de la UEMS es armonizar la formación de los especialistas a nivel europeo garantizando la calidad y la mejora continua. Actualmente, 33 de las 53 especialidades recogidas en la UEMS ya cuentan con exámenes europeos, y algunos estados miembro de la UE los han adoptado voluntariamente como parte de su sistema de evaluación. La participación en estos exámenes, a parte del beneficio individual para los residentes, proporciona elementos comparativos entre países y unidades docentes.

La sección se muestra a favor de promover el desarrollo de exámenes europeos para la especialidad de Medicina del Trabajo, y se propone trabajar el diseño del currículo en el que se basará el examen en paralelo con la revisión de los requisitos de formación europeos (European Training Requirements-ETR) de la especialidad de Medicina del Trabajo requeridos por la UEMS.

Durante la reunión se anunció que la sección es ya uno de los 99 socios oficiales de la Agencia Europea para la Seguridad y la Salud en el Trabajo (OSHA-Bilbao). En relación a la Agencia Europea se informó de $\mathrm{OiRA}^{6}$, una herramienta online sencilla y gratuita para facilitar la evaluación de riesgos especialmente di- rigida a las Pequeñas y Medianas Empresas. También se informó de que la próxima campaña«Trabajos saludables» de 2018-2019 estará dedicada a las sustancias peligrosas con el fin de aumentar la sensibilización y promover una cultura de prevención en los lugares de trabajo de toda la UE, centrando la atención en grupos específicos de trabajadores.

La sección mantiene los contactos con EASOM, con sus cursos anuales de escuela de verano, y con el "European Trade Union Institute" (ETUI), cuyas líneas de investigación principales, aparte de cancerígenos y mutágenos, apuntan hacia temas ergonómicos y de trastornos musculoesqueléticos, y hacia el establecimiento de requisitos mínimos para los servicios de prevención.

También se recordó que la próxima reunión del ICOH (International Committee in Occupational Health) será en Dublín en abril y mayo de 2018 y las inscripciones ya están abiertas.

Las actas de las reuniones de la Sección de Medicina del Trabajo de la UEMS son públicas, y junto con las presentaciones utilizadas en la reunión, se pueden consultar en la página web de la Sección: http://www.uems-occupationalmedicine.org.

La próxima reunión será en octubre en Leuven y en ella tendrán lugar las elecciones a miembros de junta de la sección.

\section{BIBLIOGRAFIA}

1. Unión Europea de Médicos Especialistas (UEMS) [página principal en Inter net]. Bruselas: Union Européenne des Médecins Spécialistes. European Union of Medical Specialists. [citado 25 Jul 2016]. Disponible en: https://www.uems.eu/ 2. Sección de Medicina del Trabajo de la UEMS [página principal en Internet]. Bruselas: Sección de Medicina del Trabajo de la UEMS [citado 9 Mar 2016]. Disponible en: http://www.uems-occupationalmedicine.org

3. European Junior Doctors [página principal en Internet]. Bruselas: European Ju nior Doctors. [citado 9 Mar 2016]. Disponible en: http://www.juniordoctors.eu/ 4. European Association of Schools of Occupational Medicine [página principal en Internet]. Bruselas: European Association of Schools of Occupational Medicine. [citado 9 Oct 2016]. Disponible en: http://www.easom.eu/

5. The Council for European Specialists Medical Assessment, CESMA [inter net]. Bruselas: Union Européenne des Médecins Spécialistes. European Union of Medical Specialists.[citado 12 jun 2017]. Disponible en: https://www.uems. eu/areas-of-expertise/postgraduate-training/cesma

6. OiRA: herramientas sencillas y gratuitas para facilitar la evaluación de riesgos [Internet]. Bilbao: Agencia Europea para la Seguridad y la Salud en el Trabajo [citado 12 Jun 2017]. Disponible en: https://osha.europa.eu/es/tools-and-publications/oira 


\section{SECCIÓ DE MEDICINA DEL TREBALL DE LA UNIÓ EUROPEA DE METGES ESPECIALISTES (UEMS)}

La primera reunió de 2017 de la secció de Medicina del Treball de la Unió Europea de Metges Especialistes (UEMS) ${ }^{1,2}$ va tenir lloc a Hèlsinki els dies 26 i 27 de maig amb assistència de 18 representants. Els països representats van ser Àustria, Bèlgica, Dinamarca, Eslovènia, Espanya, Finlàndia, Itàlia, Irlanda, Luxemburg, Noruega, Països Baixos, Polònia, Portugal, República Txeca, Romania i Suïssa. També va assistir la representant dels residents de Medicina del Treball (European Junior Doctors) ${ }^{3}$, un representant de EASOM (European Association of Schools of Occupational Medicine) $)^{4}$ i el tresorer de la UEMS.

La presidenta de la secció, Alenka Skerjanc, va destacar que aquesta reunió coincideix amb diversos aniversaris, com els 100 anys d'independència de Finlàndia, 70 anys de l'Institut Finlandès de Salut Laboral, i 20 anys de la secció de Medicina del Treball de la UEMS (la pròpia UEMS complirà 60 anys el proper any).

En aquesta ocasió, la Secció de Medicina del Treball de la UEMS va tenir l'honor de comptar amb la presència del Professor Jorma Rantanen, President de la Comissió Internacional de Salut Ocupacional (ICOH) entre 2003 i 2006, director general de l'Institut Finlandès de Salut Ocupacional fins a 2003, i assessor expert de l'Organització Mundial de la Salut (OMS), l'Organització Internacional del Treball (OIT) i de la Unió Europea (UE). El professor Rantanen va fer una presentació de la seva perspectiva sobre "Els reptes als serveis de salut laboral mundials i europeus en l'era de la globalització" en la que va emfatitzar que, tot i les deficiències, Europa és clarament el líder mundial en salut laboral, per davant dels Estats Units, i molt per davant de la resta de països. Això ens dóna una responsabilitat mundial, ja que molts miren a Europa com a referent. Tot i que la globalització és un concepte complex, hi ha instruments per mesurar-la, com l'índex de Zuric i el de Maastricht, i tots dos mostren que 12 països europeus (entre ells Espanya) estan entre els 15 primers en qüestió de globalització. En relació a les empreses, ha indicat que la tendència és que cada vegada hi hagi menys multinacionals, però més grans i poderoses, mentre que les petites i mitjanes empreses continuen sent les que major nombre de llocs de treball ofereixen a nivell mundial. En relació als riscos, aquests són principalment psicosocials a Europa (inseguretat laboral, estrès crònic, jornades laborals llargues, retallades en personal, lideratges tòxics, envelliment de la població treballadora amb la necessitat d'adaptacions tant físiques com mentals, etc.), mentre que a Àsia i Àfrica continuen predominant els riscos clàssics. Als països desenvolupats les millores en seguretat $i$ salut laboral han reduït els riscos clàssics, i les exposicions han disminuït (encara que no desaparegut); també comptem amb mètodes més sensibles per detectar-los de manera que la realització d'avaluació de riscos s'està fent més complexa. Tot això ha contribuit a que disminueixin els accidents mortals a Europa, però continua havent una enorme infradeclaració de malalties professionals, i molt més encara si ens referim a les malalties relacionades amb el treball.

Arch Prev Riesgos Labor 2017; 20 (4): 221-224
Però des d'una perspectiva global, s'estima que més de 2 milions de persones moren cada any per malalties relacionades amb el treball, i més de 300.000 (equivalent a 1.000 morts al dia) per accidents de treball. A nivell mundial, la cobertura de serveis de salut laboral per a la població treballadora es calcula en un $15.5 \%$ com a màxim, però a més l'accés és més limitat precisament per a aquells treballadors que ho necessitarien més.

La presentació del professor Rantanen està disponible com a annex 2 a l'acta de la reunió que es pot trobar, com és habitual, a la pàgina web de la secció.

A continuació el Professor Kari Reijula, de la Universitat d'Hèlsinki i l'Institut Finlandès de Salut Ocupacional, va fer un resum de la situació de la salut laboral a Finlàndia, país amb una població de 5.5 milions de persones i una població activa de 2.6 milions.

La Medicina del Treball a Finlàndia requereix una formació especialitzada de 6 anys i és la segona especialitat més gran al país; sempre ha tingut una gran presència i fortalesa com a especialitat, i, encara que actualment es troba qüestionada aquesta supremacia, sembla que aguantarà a un intent de canvi legislatiu el debat del qual està en curs. Els serveis de salut laboral finlandesos poden ser propis, aliens o públics i un $79 \%$ dels treballadors (1.9 milions). Amb un pressupost de 800 milions d'euros a l'any, el finançament prové en un 99\% de les cotitzacions d'empreses i treballadors i constitueix un sistema amb una rica distribució geogràfica en el territori i d'alta eficiència, treballant en moltes ocasions mà a mà amb els metges de família. De fet, els serveis de salut ocupacional a Finlàndia aborden no només els aspectes preventius i de vigilància de la salut, sinó que també tenen un paper assistencial. Aquest paper es centra principalment en el diagnòstic i tractament de malalties professionals i relacionades amb el treball així com accidents de treball, però també cobreix la detecció i tractament de patologia comuna prevalent entre els treballadors de les empreses a les que donen cobertura. Per això, a més de metges i infermers del treball compten amb fisioterapeutes i psicòlegs.

A continuació el secretari general de la UEMS, Bernard Maillet, va fer un resum de les últimes activitats de la UEMS a nivell central, i la representant dels residents de Medicina del Treball va exposar els resultats de l'enquesta sobre formació en els diferents països europeus.

El representant danès, encarregat de la pàgina web de la secció, ha informat que les visites al web han augmentat sensiblement en l'últim any (probablement gràcies al fet que els països han introduït els enllaços a les seves respectives webs) i recorda que totes les actes, des de la primera fa 20 anys (Glasgow, 25-4-1997) a l'última, estan disponibles amb caràcter públic al web de la secció.

El següent punt que es va tractar va ser en relació als exàmens europeus promoguts per la UEMS d'acord amb les normes CES. $\mathrm{MA}^{5}$ que són compartides per totes les especialitats.

Un dels objectius primordials de la UEMS és harmonitzar la formació dels especialistes a nivell europeu garantint la qualitat i la millora contínua. Actualment, 33 de les 53 especialitats reco- 
llides en la UEMS ja compten amb exàmens europeus, i alguns estats membre de la UE els han adoptat voluntàriament com a part del seu sistema d'avaluació. La participació en aquests exàmens, a part del benefici individual per als residents, proporciona elements comparatius entre països i unitats docents.

La secció es va mostrar a favor de promoure el desenvolupament d'exàmens europeus per a l'especialitat de Medicina del Treball, i es va proposar treballar el disseny del currículum en el qual es basarà l'examen en paral.lel amb la revisió dels requisits de formació europeus (European Training Requirements-ETR) de l'especialitat de Medicina del Treball requerits per la UEMS.

Durant la reunió es va anunciar que la secció és ja un dels 99 socis oficials de l'Agència Europea per a la Seguretat i la Salut en el Treball (OSHA-Bilbao). En relació a l'Agència Europea es va informar d'OiRA 6 , una eina en línia senzilla i gratuïta per facilitar l'avaluació de riscos especialment dirigida a les petites i mitjanes empreses. També es va informar que la propera campanya «Treballs saludables» de 2018-2019 estarà dedicada a les substàncies perilloses per tal d'augmentar la sensibilització i promoure una cultura de prevenció en els llocs de treball de tota la UE, centrant l'atenció en grups específics de treballadors.

La secció manté els contactes amb EASOM, amb els seus cursos anuals d'escola d'estiu, i amb el "European Trade Union Institute" (ETUI), les línies d'investigació principals del qual, a part de cancerígens i mutàgens, apunten cap a temes ergonòmics i de trastorns musculoesquelètics, i cap a l'establiment de requisits mínims per als serveis de prevenció.

També es va recordar que la propera reunió del ICOH (International Committee in Occupational Health) serà a Dublín l'abril i maig de 2018 i les inscripcions ja estan obertes.

Les actes de les reunions de la Secció de Medicina del Treball de la UEMS són públiques, i juntament amb les presentacions utilitzades en la reunió, es poden consultar a la pàgina web de la Secció: http://www.uems-occupationalmedicine.org.

La propera reunió serà a l'octubre a Leuven i en ella tindran lloc les eleccions a membres de junta de la secció.

\section{BIBLIOGRAFÍA}

1. Unió Europea de Metges Especialistes (UEMS) [pàgina principal a Internet]. Brussel.les: Union Européenne des Médecins Spécialistes. European Union of Medical Specialists. [citat 25 juliol 2016]. Recuperat a partir de: https://www. uems.eu/.

2. Secció de Medicina del Treball de la UEMS [pàgina principal a Internet]. Brussel.les: Secció de Medicina del Treball de la UEMS [citat 9 març 2016]. Recuperat a partir de: http://www.uems-occupationalmedicine.org.

3. European Junior Doctors [pàgina principal a Internet]. Brussel.les: European Junior Doctors. [citat 9 març 2016]. Recuperat a partir de: http://www.juniordoctors.eu/.

4. European Association of Schools of Occupational Medicine [pàgina principal a Internet]. Brussel.les: European Association of Schools of Occupational Medicine. [citat 9 octubre 2016]. Recuperat a partir de: http://www.easom.eu/. 5. The Council for European Specialists Medical Assessment, CESMA [in ternet]. Brussel.les: Union Européenne des Médecins Spécialistes. European Union of Medical Specialists.[citat 12 juny 2017]. Recuperat a partir de: https:// www.uems.eu/areas-of-expertise/postgraduate-training/cesma.

6. OiRA: herramientas sencillas y gratuitas para facilitar la evaluación de riesgos [Internet]. Bilbao: Agencia Europea para la Seguridad y la Salud en el Trabajo [citat 12 juny 2017]. Recuperat a partir de: https://osha.europa.eu/es/tools-andpublications/oira.

INVESTIGACIÓN DE ACCIDENTES DE TRABAJO. METODOLOGÍA E IMPLANTACIÓN

9 de noviembre de 2017, Ávila

Información:

Unidad de Seguridad y Salud Laboral

C/ Segovia, 25, 05005 Ávila, España

Tel.: 920355800

Fax.: 920355807

www.trabajoyprevencion.jcyl.es

PRL EN EL SECTOR DE TRANSPORTE POR CARRETERA. RIESGOS ESPECÍFICOS DE LOS CONDUCTORES PROFESIONALES

16 de noviembre de 2017, A Coruña

Información:

Centro ISSGA de A Coruña, Rúa Doutor Camilo Veiras 8, 15006 A Coruña, España

Tel.: 981182329

Fax.: 981182332

issga.coruna@xunta.gal

http://issga.xunta.gal/portal/contido/o-issga/index.html 